\title{
EVALUASI PENGARUH LAMANYA PEMBERIAN ASI SAJA TERHADAP PERTUMBUHAN ANAK \\ Suatu Studi di Kecamatan Ledo, Kabupaten Bengkayang, Provinsi Kalimantan Barat
}

\author{
Lepita, ${ }^{1}$ Hadyana Sukandar, ${ }^{2}$ Firman F. Wirakusumah ${ }^{3}$ \\ ${ }^{1}$ Program Studi Magíster Kebidanan, ${ }^{2}$ Bagian Epidemiologi \& Biostatistika, \\ ${ }^{3}$ Bagian Obstetri \& Ginekologi Fakultas \\ Kedokteran Universitas Padjadjaran/Rumah Sakit Hasan Sadikin
}

\begin{abstract}
ABSTRAK
Air susu ibu (ASI) merupakan makanan yang kaya akan gizi dan sangat penting untuk pertumbuhan anak. Terganggunya pertumbuhan anak diawali dengan kekurangan gizi yang dapat diatasi dengan memberikan ASI saja sejak lahir. Tujuan penelitian ini untuk mengetahui pengaruh lamanya pemberian ASI saja pada pertumbuhan anak. Faktor yang dilihat adalah berat badan dan tinggi badan anak. Penelitian ini merupakan penelitian kohort retrospektif yaitu mencari efek yang muncul pada balita usia antara 12 sampai 36 bulan yang ketika bayinya menggunakan ASI saja di wilayah Kecamatan Ledo. Jumlah subjek yang diteliti sebanyak 101 anak. Sampel diambil dengan teknik cluster berdasarkan kriteria inklusi. Analisis statistik memakai analisis varians, uji Mann-Whitney, Kruskal-Wallis, dan korelasi regresi. Hasil penelitian ini menunjukkan bahwa lamanya pemberian ASI saja mempengaruhi pertumbuhan anak berdasarkan persen terhadap median Berat Badan (BB)/Usia (U) dan Berat Badan (BB)/Tinggi Badan (TB) $(p<0,001)$; tidak tampak pengaruh lamanya pemberian ASI dengan pertumbuhan anak berdasarkan persen terhadap median TB/U baku rujukan WHO-NCHS $(p>0,05)$. Kesimpulan pada penelitian ini adalah lamanya pemberian ASI saja berpengaruh positif terhadap pertumbuhan yang diukur berdasarkan persen terhadap median BB/U dan BB/TB baku rujukan $\mathrm{WHO}-\mathrm{NCHS}$.
\end{abstract}

Kata kunci: Lamanya pemberian ASI, pertumbuhan anak, antropometri

\section{EVALUATION THE IMPACT BREASTFEEDING PERIOD OF TIME TO THE CHILD GROWTH \\ A Study In Ledo Subdistrict, Bengkayang Regency, West Kalimantan Province}

\begin{abstract}
Breastfeeding is rich food nutrient and it is very important for the child growth. Neonatal growth disorders, it is initially revealed from the beginning by a lack of nutrient. The lack of nutrient can be minimized by giving breastfeeding since the first living without any additional food. The objective of this study was to know the impact of length duration influenced of breastfeeding to the child growth that was seen from the child's body weight and body height. This study designed as a retrospective cohort looking for an effect of weight and height growth of subject child age between 12 to 36 months used to have only breastfeeding in Ledo. The study carried out to 101 children. The samples collected by cluster technique, the inclusion criteria had been determined. Statistical analysis used, varians, Mann-Whitney, Kruskal-Wallis, and analysis regression. The result of study, it was shown that the duration of breastfeeding affect of child growth significantly different; the percentage of median body weight to age vs body weight to body height referred to WHO-NCHS standard $(p<0.001)$; but there were no any correlation on the percentage of median body height to age referred to WHO-NCHS standard (>0.05). Conclusion: duration of breastfeeding has positive effect to the growth which is measured based on the percentage of median body weight/age and body weight/body height referred to WHO-NCHS standard.
\end{abstract}

Key words: Duration of breastfeeding, child growth, anthropometry

\author{
Alamat Korespondensi: \\ Lepita, M. Keb \\ Program Pascasarjana Fakultas Kedokteran \\ Universitas Padjadjaran, \\ JI. Sungai Raya Dalam Komplek Taman Sungai II No. A46, Pontianak \\ Telp:081522624008, e-mail:ma_nda1@yahoo.co.id
}




\section{PENDAHULUAN}

Air susu ibu (ASI) eksklusif merupakan makanan yang diberikan pada anak tanpa makanan tambahan lain sampai usia 6 bulan. ASI merupakan makanan kaya gizi yang penting untuk pertumbuhan anak. Gangguan pertumbuhan anak biasanya diawali dengan kekurangan gizi dengan memakai indikator antropometri. ${ }^{1-3}$

Beberapa penelitian telah melaporkan keuntungan pemberian ASI pada masa awal pertumbuhan bayi.

Di Kecamatan Ledo Kabupaten Bengkayang Kalimatan Barat program ASI eksklusif belum memasyarakat, karena belum semua wilayah terjangkau promosi ASI eksklusif. Keadaan bayi kurang gizi menjadi masalah kesehatan masyarakat di Kabupaten Bengkayang. Berdasarkan masalah yang ditemukan maka peneliti tertarik untuk melakukan penelitian mengenai pengaruh lamanya pemberian ASI saja terhadap pertumbuhan anak.

\section{SUBJEK DAN METODE}

Penelitian ini dilakukan dengan rancangan kohort retrospektif yaitu mencari efek yang muncul pada balita yang menggunakan ASI saja dalam kehidupan pertama pada usia antara 0-6 bulan. Penelitian dilakukan di Kecamatan Ledo, Kabupaten Bengkayang, Kalimantan Barat dari bulan September sampai dengan Desember 2007.

Populasi target adalah seluruh anak yang berusia 12-36 bulan, sedangkan populasi terjangkau adalah seluruh balita yang berusia antara 12-36 bulan yang ada di Kecamatan Ledo, Kabupaten Bengkayang, Kalimantan Barat. Kriteria inklusi: balita yang ketika bayi mendapatkan ASI, balita yang berada di Kecamatan Ledo, usia balita berkisar antara 12-36 bulan. Kriteria eksklusi adalah balita yang terkena penyakit tuberkulosis paru, malaria, tifus, dan demam berdarah saat penelitian.
Alat yang digunakan dalam penelitian ini adalah formulir data penelitian disesuaikan dengan format indikator antropometri, dacin, dan pita ukur.

Data hasil penelitian dianalisis dengan analisis varians untuk mencari perbedaan ratarata lebih dari dua kategori, uji Mann-Whitney dan Kruskal-Wallis untuk mengetahui rata-rata dua proporsi, sedangkan analisis korelasi dan regresi untuk mencari hubungan lamanya pemberian $\mathrm{ASI}$ dengan persen terhadap median Berat Badan (BB)/Usia, Tinggi Badan (BB)/Usia (U) dan BB/TB baku rujukan World Health Organization-National Center for Health Statistic (WHO-NCHS). Semua pengujian analisis data menggunakan program SPSS versi 12.00 .

\section{HASIL PENELITIAN}

Subjek pada penelitian adalah 101 anak berusia antara 12-36 bulan. Terhadap subjek penelitian dilakukan anamnesis serta pengukuran berat badan dan tinggi badan. Hasil analisis pertumbuhan anak dikelompokkan sesuai dengan status gizi anak berdasarkan persen terhadap median $\mathrm{BB} / \mathrm{U}, \mathrm{TB} / \mathrm{U}$, dan $\mathrm{BB} / \mathrm{TB}$ baku rujukan WHO-NCHS.

Hasil analisis perbandingan persen terhadap median BB/U, TB/U dan BB/TB baku rujukan WHO-NCHS terhadap usia anak dan lamanya pemberian ASI saja yang sudah diklasifikasikan tercantum dalam Tabel 1.

Untuk menyatakan hubungan lamanya pemberian $\mathrm{ASI}$ saja dengan persen terhadap median BB/U, TB/U, dan BB/TB baku rujukan WHO-NCHS, dilakukan perhitungan dengan menggunakan analisis korelasi (Tabel 2).

Hasil analisis hubungan lamanya pemberian $\mathrm{ASI}$ saja dengan $\mathrm{BB} / \mathrm{U}$ dan $\mathrm{BB} / \mathrm{TB}$ anak sangat bermakna dengan nilai $p<0,01$, sedangkan hubungan lamanya pemberian ASI saja dengan TB/U anak tidak bermakna dengan nilai $p>0,05$. Pertumbuhan berdasarkan persen terhadap median $\mathrm{BB} / \mathrm{U}$ mempunyai kesesuaian dengan persen terhadap median BB/TB dalam hubungan dengan lamanya pemberian ASI saja.

Tabel 1 Pertumbuhan Anak Berdasarkan Persen Terhadap Median BB/U, TB/U, dan BB/TB Baku Rujukan WHO-NCHS

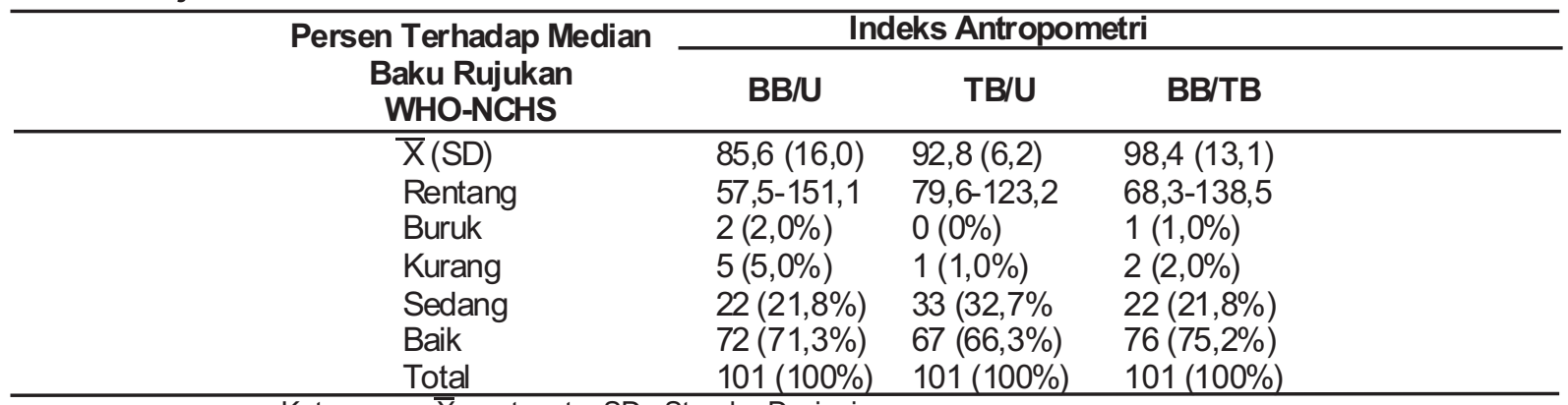


Hasil analisis multipel regresi menunjukkan bahwa lama pemberian ASI saja mempengaruhi pertumbuhan berdasarkan persen terhadap median BB/U dan BB/TB baku rujukan WHO-NCHS bermakna dengan nilai $p<0,01$, sedangkan lama pemberian ASI saja terhadap pertumbuhan berdasarkan persen median TB/U tidak bermakna dengan nilai $p>0,05$. Hasil analisis ini menunjukkan ada pengaruh lamanya pemberian ASI saja terhadap

Tabel 2 Hubungan Lamanya Pemberian ASI Saja dengan Persen Terhadap Median BB/U, TB/U, dan BB/TB Baku Rujukan WHO-NCHS

\begin{tabular}{lcc}
\hline \multicolumn{1}{c}{ Hubungan Variabel } & Koefisien Korelasi $(\mathbf{r})$ & Nilai $\mathbf{p}$ \\
\hline $\begin{array}{l}\text { Lamanya pemberian ASI saja dengan } \\
\text { persen median BB/U }\end{array}$ & $0,249^{(*)}$ & 0,012 \\
$\begin{array}{l}\text { Lamanya pemberian ASI saja dengan } \\
\text { persen median TB/U }\end{array}$ & 0,005 & 0,53 \\
$\begin{array}{l}\text { Lamanya pemberian ASI saja dengan } \\
\text { persen median BB/TB }\end{array}$ & $0,352^{(*)}$ & 0,01 \\
\hline
\end{tabular}

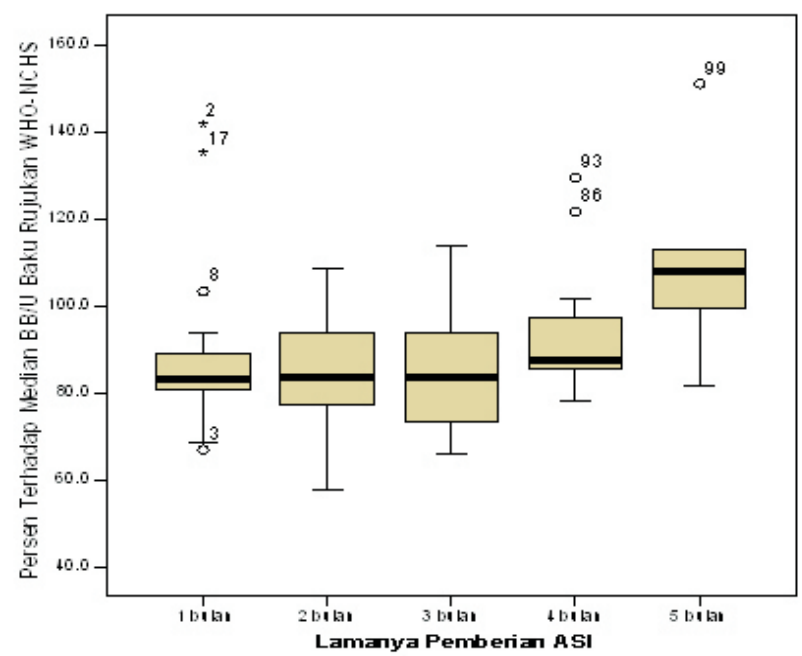

Keterangan: Koefisien Korelasi $\left(r_{\text {pearson }}\right)=0,249^{\left({ }^{*}\right)} ; p=0,012$

Gambar 1 Hubungan Lamanya Pemberian ASI Saja dengan Persen Terhadap Median BB/U Baku Rujukan WHO-NCHS

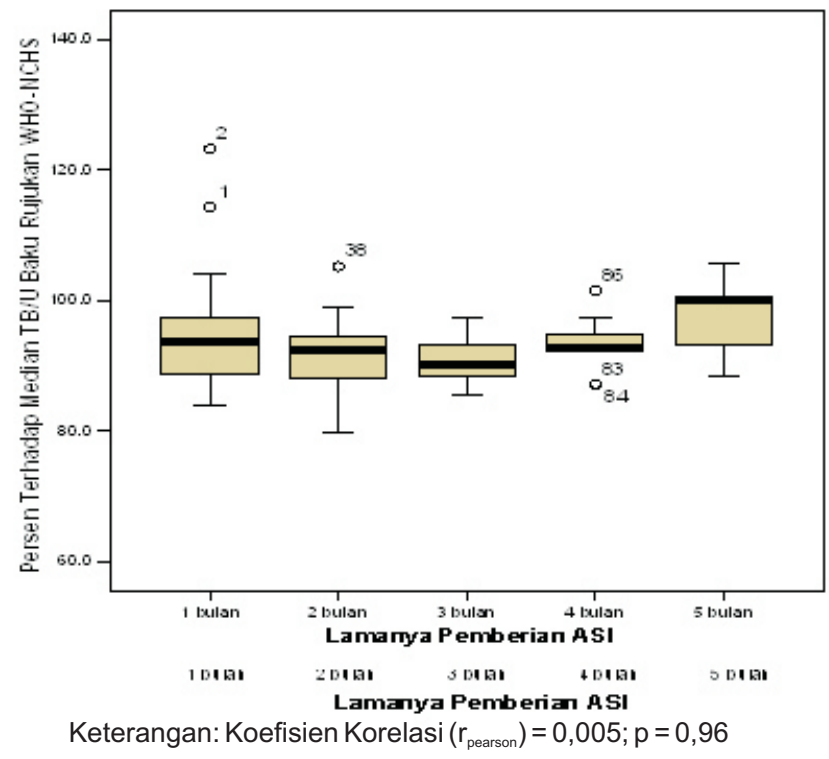

Gambar 2 Hubungan Lamanya Pemberian ASI Saja dengan Persen Terhadap Median TB/U Baku Rujukan WHO-NCHS 


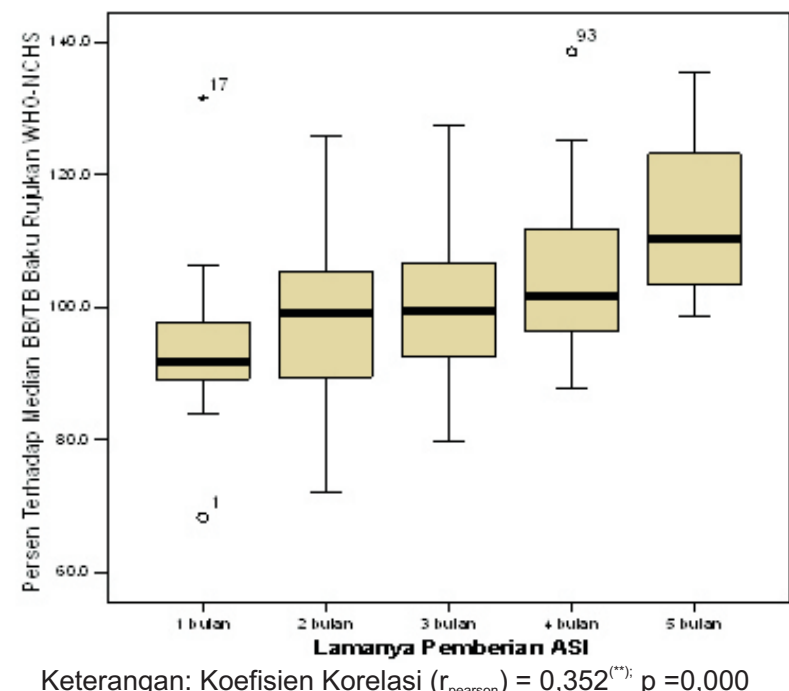

\section{Gambar 3 Hubungan Lamanya Pemberian ASI Saja dengan Persen Terhadap Median BB/TB Baku Rujukan WHO-NCHS}

pertumbuhan anak berdasarkan persen terhadap median indeks antropometri WHONCHS.

\section{PEMBAHASAN}

Anak dengan gizi sedang jumlahnya cukup banyak, kemungkinan besar dapat mengarah ke gizi kurang jika tidak segera diatasi. Kondisi ini dapat terjadi karena usia anak antara 12-36 bulan akan mengalami penurunan status gizi sampai dengan usia 48-59 bulan. Harapan pemerintah pada anak-anak Indonesia agar terbebas dari kekurangan gizi masih belum tercapai, karena berbagai faktor yang menghambat upaya mengatasi status gizi, misalnya tidak memberikan ASI eksklusif pada anak seperti tampak pada Tabel 1 hasil penelitian ini. ${ }^{1-4}$

Kekurangan gizi dapat diminimalisir dengan pemberian ASI. Beberapa peneliti juga mengungkapkan bahwa ada perbedaan pertumbuhan pada anak yang mendapat ASI eksklusif dengan anak yang tidak mendapat ASI eksklusif. Upaya yang dilakukan pemerintah adalah menggalakkan Gerakan Nasional PP. ASI dengan menjamin setiap ibu memberikan anaknya ASI eksklusif sampai dengan usia 6 bulan, agar pertumbuhan anak baik. . $^{6-8}$

Perbandingan pertumbuhan berdasarkan persen terhadap median BB/ $\mathrm{U}$, TB/U dan $\mathrm{BB} / \mathrm{TB}$ baku rujukan WHO-NCHS dengan karakteristik usia anak tidak bermakna dengan nilai $p>0,05$. Beberapa hasil penelitian yang pernah dilakukan menyatakan bahwa usia anak tidak bermakna terhadap pertumbuhan anak..$^{9-11}$

Lama pemberian ASI saja dengan perbandingan pertumbuhan berdasarkan persen terhadap median BB/U, TB/U dan BB/TB baku rujukan WHO-NCHS bermakna dengan nilai $p<0,05$, yang berarti ada pengaruh pertumbuhan berdasarkan persen terhadap lama pemberian ASI. ${ }^{11-13}$

Beberapa peneliti menyatakan bahwa ASI mempengaruhi pertumbuhan anak yang dinilai dengan mengukur BB dan TB. Meskipun demikian pemberian ASI saja sampai dengan usia anak 6 bulan di negara kita hanya sekitar $14 \%$. Seperti yang diketahui bahwa ASI eksklusif mempunyai daya imun yang cukup tinggi dan gizi yang kompleks, sehingga membantu menekan angka kematian bayi hingga $13 \%$, dengan dasar asumsi dari jumlah penduduk 219 ribu jiwa dapat membantu menyelamatkan sebanyak 30 ribu. Rendahnya pemberian ASI eksklusif dapat juga memicu rendahnya pertumbuhan dan dapat mengakibatkan daya imun anak menjadi rendah sehingga mudah terserang penyakit infeksi. $^{2,12,14,15}$

Lama pemberian ASI saja berdasarkan persen terhadap median BB/U dan BB/TB baku rujukan $\mathrm{WHO}-\mathrm{NCHS}$ bermakna dengan nilai $p<0,05$, yang berarti ada hubungan lama pemberian ASI dengan persen terhadap median $\mathrm{BB} / \mathrm{U}$ dan BB/TB baku rujukan WHO-NCHS seperti terlihat pada Tabel 3 dan Gambar 1 dan 2. Beberapa penelitian mengenai pemberian ASI eksklusif menunjukkan bahwa ASI sangat penting untuk pertumbuhan anak, paling jelas terlihat dari kenaikan BB anak, dari hasil penelitian tersebut menunjukkan ada perbedaan pertumbuhan pada anak yang mendapatkan ASI dan yang tidak mendapatkan ASI. Peningkatan BB tersebut karena ASI mengandung nilai gizi yang cukup kompleks sehingga dapat memenuhi kebutuhan bayi setiap hari. ${ }^{2,14,15}$

Pertumbuhan anak juga dapat dinilai dengan persen terhadap median BB/TB baku rujukan WHO-NCHS. Pertumbuhan antara BB dan TB ada hubungan yang linear jika pertum- 
buhan anak normal. Pemberian ASI saja juga mempengaruhi peningkatan BB/TB agar pertumbuhan seimbang. ${ }^{1,2,9,11,13}$

Lamanya pemberian ASI saja dengan persen terhadap median TB/U baku rujukan WHO-NCHS tidak bermakna dengan nilai $p>0,05$, yang berarti tidak ada hubungan lamanya pemberian ASI saja dengan persen terhadap median TB/U baku rujukan WHO-NCHS seperti terlihat pada Tabel 3 dan Gambar 1. Efek lamanya pemberian ASI lambat mempengaruhi TB anak, meskipun demikian komponen yang membantu peningkatan tinggi anak ada pada ASI. Diharapkan agar ibu-ibu dapat memberikan ASI dari 0 sampai 24 bulan agar kebutuhan gizi untuk pertumbuhan anak terpenuhi. Kerugian yang dapat ditemukan jika ASI tidak diberikan adalah terjadi gangguan pertumbuhan akibat kekurangan gizi dan protein yang efeknya terlihat dari hambatan peningkatan TB anak. ${ }^{9,11,12,13,15}$

Lamanya pemberian ASI bermakna dengan nilai $p<0,01$ yang berarti ada pengaruh antara lama pemberian ASI saja terhadap pertumbuhan berdasarkan persen median $\mathrm{BB} / \mathrm{U}$ dan BB/TB baku rujukan WHO-NCHS. Pengaruh $\mathrm{ASI}$ terhadap $\mathrm{BB} / \mathrm{U}$ dan $\mathrm{BB} / \mathrm{TB}$ sangat nyata sekali dibandingkan variabel-variabel lain, karena seperti yang telah dijelaskan bahwa ASI itu sangat mempengaruhi pertumbuhan anak karena nilai gizinya yang cukup kompleks. ${ }^{6,9,10}$

Pada TB/U lamanya pemberian ASI tidak bermakna yang berarti tidak ada pengaruh lama pemberian ASI saja terhadap pertumbuhan berdasarkan persen median TB/U baku rujukan WHO-NCHS, tetapi efek yang mungkin muncul jika anak tidak diberikan ASI, adalah anak akan mengalami kekurangan gizi kronik dan peningkatan TB anak tidak sesuai dengan usia pada masa yang akan datang. TB pada suatu waktu merupakan hasil pertumbuhan yang kumulatif dan karena itu memberikan gambaran riwayat gizi yang lalu. ${ }^{2,4,10}$

Seperti yang dikatakan dalam PP ASI anak sebaiknya diberikan ASI eksklusif sampai dengan 6 bulan dan selanjutnya sampai dengan 24 bulan ditambah dengan makanan pengganti ASI sesuai dengan usia anak. Anak yang diberi ASI pertumbuhannya akan lebih baik dibandingkan dengan anak yang tidak diberi ASI. Pertumbuhan anak berhubungan dengan kebutuhan gizi, jika gizi yang diperlukan dalam proses pertumbuhan tidak seimbang, maka anak akan mengalami gizi buruk atau kurang yang dialami pada masa pertumbuhan balita. Meskipun kebutuhan gizi pada anak sangat bervariasi tetapi kebutuhan yang diberikan harus seimbang. ${ }^{3,4,10}$

Harapan minimal penelitian ini adalah diperoleh rujukan agar dapat menjadi pembanding penelitian lainnya. Kesimpulan dalam penelitian ini adalah terdapat pengaruh lamanya pemberian ASI saja terhadap pertumbuhan anak berdasarkan persen terhadap median $\mathrm{BB} / \mathrm{U}$ dan $\mathrm{BB} / \mathrm{TB}$ baku rujukan WHO-NCHS.

\section{DAFTAR PUSTAKA}

1. Soetjiningsih. Air susu ibu petunjuk untuk tenaga kesehatan. Jakarta: EGC; 1997.

2. $\mathrm{Fu} \mathrm{Z}$, Chang $\mathrm{S}, \mathrm{He} \mathrm{W}$, Fugang. Exclusive breastfeeding and growth of infant under 4 months in China. J Trop Pediatr. 2000 September $1 ; 29: 275-8$.

3. Dinkes Kalbar. pedoman pemberian ASI eksklusif sampai usia 6 bulan. Dinkes Kalbar, 2006.

4. Supariasa IDN, Bakri B, Fajar I. Penilaian status gizi. Jakarta: EGC; 2002.

5. Wardiman II, Handini H, Supriyadi RW, Hadis LA. makanan untuk tumbuh kembang otak. Jakarta: Grafika Multi Warna; 2003.

6. Soetjiningsih. Pertumbuhan dan perkembangan anak. Jakarta: EGC; 1997.

7. Bagian Gizi. Laporan seksi Gizi. Dinkes Propinsi Kalimantan Barat; 2006.

8. Depkes RI. Buku panduan manajemen laktasi. Jakarta: Dit. Gizi Masyarakat; 2001.

9. WHO Expert Committee. Physical status the use and interpretation of anthropometry. Geneva: WHO Technical Report Series 854; 1995.

10. Husaini YK. Antropometri sebagai indeks gizi dan kesehatan masayarakat. Medika. 1997; XXIII:269.

11. Hadyana Sukandar. Pengaruh berat lahir rendah terhadap pertumbuhan dan kualitas hidup anak pada usia remaja, dari kohor bayi yang di lahirkan pada periode tahun 1988-1989 di Kecamatan Tanjungsari, Kabupaten Sumedang. [disertasi]. Jakarta: Universitas Indonesia; 2006.

12. Dhamayanti M. Pendidikan ibu sebagai faktor dominan yang mempengaruhi pola pertumbuhan anak usia 15-18 bulan di daerah kumuh kota Bandung. MKB. 2006; XXXVIII:20-6.

13. Yanwirasti. Pertumbuhan bayi yang menerima air susu ibu secara eksklusif dan non eksklusif di daerah perkotaan Sumatera Barat. MKI. 2004; 53:6.

14. Eckhardt CL, Rivera J, Adair LS, Reynaldo M. Full breastfeeding for at least four months has differential effects on growth before and after six months of age among children in a Mexican community. Am J Clin Nutr. 2001;2:304-9.

15. Bartington S, Griffiths LJ, Tate AR, Dezateux C. Are breastfeeding rates higher among mothers delivering in baby friendly. Int J. 2006; 35(5):117886. 